\title{
Hemodynamic Monitoring with the Clinic: Back to Basics
}

Keywords: Shock; Critical care; Hemodynamic monitoring; Clinical

\begin{abstract}
The state of shock is a frequent diagnosis in the critical areas, prehospital, emergency, operating room and intensive care unit, clinical hemodynamic monitoring is essential to make the diagnosis of tissue hypoperfusion and its causes, in addition to guiding therapeutics, the challenge It consists of performing adequate monitoring with the tools available in our service, recent studies show that the data found with the clinic have good reliability when compared to other types of monitoring such as invasive and semi-invasive.
\end{abstract}

\section{Introduction}

In any clinical scenario that involves facing a patient in a state of shock, and regardless of the area in which they are (emergencies, hospitalization, operating room or intensive care unit), early recognition of an inadequate perfusion state will always be necessary to start immediate treatment and achieve a reduction in morbidity and mortality [1]. The objective will be to achieve adequate decisionmaking as soon as possible and establish a therapeutic intervention in order to restore normal hemodynamics and correct the cause that led to the demand or significant loss of global perfusion, as this can beneficially modify the course, prognosis and convalescence of the disease.

Due to excessive abuse of invasive monitoring and abandonment of the clinic, the aim of this article it's to emphasize that the clinical monitoring will always be within our reach, that is why in this review we will observe that the clinical monitoring to the patient bedside.

Clinical evaluation and physical examination are the first steps to individualize patients at risk of shock and timely detection of manifestations of inadequate tissue perfusion, the clinical evolution of the disease behaves in a multimodal manner and the sequential order is not same in all patients, but in most cases, scientific knowledge and experience return to the health personnel expert in identifying, warning signs that may be useful clinical tools to demonstrate a state of shock [2].

Hypotension is the sign attributed to the greatest importance in most cases and is considered one of the main causes or manifestations of shock, however, this can be found late in some circumstances and the degree of hypotension does not necessarily correlate with the degree of global perfusion of the patient [3].

Many common clinical alterations have been described as indicators of inadequate global tissue perfusion, and some of them reflect organic dysfunction, while others are related to the body's response to the significant stress to which it is subjected. As examples to consider with sustainable evidence we have mottled and tortuous skin, altered mental state (confusion, disorientation, seizures or coma), and oliguria (urine production $<20 \mathrm{ml} / \mathrm{h}$ or $<400$ to $600 \mathrm{ml} /$ day), data Named as clinical perfusion windows in shock, there are also other signs that accompany inadequate tissue perfusion states, these pillars not being in the strategy of identifying shock states, but

\section{Journal of}

\section{Emergency Medicine \& Critical Care}

\section{Pérez Nieto OR ${ }^{1}$, Guerrero Gutiérrez $M^{2}{ }^{2 *}$, MorgadoVillaseñor LA ${ }^{3}$, Fermín $\mathrm{JL}^{4}$, Zamarrón López $\mathrm{El}^{5}$, Soriano Orozco $\mathrm{R}^{6}$, Sánchez Díaz JS ${ }^{7}$, Uribe Moya $\mathrm{SE}^{8}$, Diaz Martínez $\mathrm{MA}^{9}$, Deloya Tomas $\mathrm{E}^{10}$ and Escarraman Martinez D ${ }^{11}$}

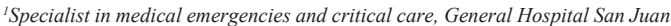
del Rio, Mexico

${ }^{2}$ Resident of first year in critical care medicine, National Institute of Cancer, Mexico

${ }^{3}$ Specialist in medical emergencies and critical care, IMSS Torreón Hospital, Mexico

${ }^{4}$ Emergency Department, Adolfo Ruiz Cortines" IMSS Veracruz, Mexico

${ }^{5}$ Specialist in medical emergencies and critical care, Hospital Cemain Tampico, Mexico

${ }^{6}$ Specialist in medical emergencies and critical care, IMSS UMAE T1, Mexico

${ }_{7}^{7}$ Veracruz. Specialist in medical emergencies and critical care, Mexico ${ }^{8}$ Department Emergency, Ángeles Lindavista Hospital, Mexico

${ }^{9}$ Department of Anesthesiology, General Hospital of Atizapan, Mexico

${ }^{10}$ General Hospital of San Juan del Rio, Qro. Specialist in medical emergencies and critical care, Mexico

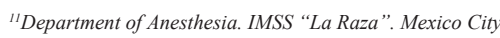

\section{Address for Correspondence}

Guerrero Gutiérrez MA, National Institute of Cancer, Resident of 1st year in Critical care. Mexico City; E-mail: manuelguerreromd@gmail.com

Submission: 11 December 2019

Accepted: 27 January 2020

Published: 07 February 2020

Copyright: () 2020 Guerrero Gutierrez MA. This is an open access article distributed under the Creative Commons Attribution License, which permits unrestricted use, distribution, and reproduction in any medium, provided the original work is properly cited.

rather related to the consequent or compensatory response of the organism given the condition, such as tachycardia, dyspnea, increased respiratory rate, jugular vein distension, and even peripheral edema [4].

The so-called hemodynamic coherence refers to the balance between the macrocirculatory and microcirculatory status, taking as an initial pillar the resuscitation interventions aimed at correcting the variables of the altered systemic hemodynamics, so that the therapeutic used is effective in the correction of regional perfusion and of the microcirculation ensuring the delivery of oxygen to the cells of the vital organs so that they are able to maintain their functional activities in what is reestablished from the cause of the shock. [5].

Four mechanisms of loss of hemodynamic coherence have been proposed, which, mostly described in patients with septic shock in whom a failure in microcirculatory recruitment is observed despite macrocirculatory resuscitation [5].

1) Heterogeneity: It is presented as a heterogeneous perfusion of the microcirculation with clogged capillaries together with perfused capillaries resulting in a heterogeneous oxygenation of the tissue cells.

2) Hemodilution: Dilution of blood in the circulation due to aggressive resuscitation with liquids results in an increase in the distance between erythrocytes and tissues 
3) Vasoconstriction/tamponade: It is the stasis of the microcirculatory flow of erythrocytes induced by circulatory failure

4) Tissue edema: Aggressive water resuscitation has the consequences of reducing the diffusion of oxygen between the transport cell (erythrocyte) and the receptor cell of the oxygen molecule.

Macrocirculation is formed by the large, medium and small caliber distribution vessels (arteries and veins) that carry blood from the heart to the periphery and back to the pulmonary circulation, and microcirculation refers to the microscopic vessels that carry the oxygen and nutrients to the tissues and eliminate cellular debris.

The normalization of systemic hemodynamic variables in late stages or in an inconsistent manner with the hemodynamic alteration of the patient does not lead to improved perfusion of microcirculation or oxygenation and instead can hinder it (eg excessive administration of volume to a septic shock due to vasodilation), excessive administration of vasopressor in systolic cardiac dysfunction).

The concept of a loss of hemodynamic coherence probably explains the negative results in the 1990s, in which several studies were conducted that aimed at normalization, or even supranormalization of all the variables that influence oxygen delivery systemic (cardiac output and arterial oxygen concentration) to coin the term hemodynamic stability, or even take as a parameter of a good resuscitation, without demonstrating significant benefit in morbidity and mortality, therefore the importance of implementing a holistic approach taking into account the clinical indices as a marker of global tissue perfusion.

The future of hemodynamic monitoring aims to be continuous, reliable, easy to interpret and that correlates adequately with the physiological parameters, in addition to being complemented with the metabolic results that together represent the real state of the patient in a unit of time with the least possible injury and invasion for the patient.

In the last decade, multiple systematized models have been proposed as a guide in early recognition of a patient in the context of inadequate tissue perfusion, as an example of a state of distributive shock such as sepsis for which the SOFA score has been proposed (qSOFA ) to identify those patients who are probably septic [] and at risk of shock mainly outside the ICU, include systolic blood pressure below $100 \mathrm{mmHg}$, respiratory rate above $22 / \mathrm{min}$ and altered mental status, if two of Every three of these signs are present, sepsis should be suspected. The qSOFA is a clear example of the simplification of diagnostic criteria with emphasis on the clinic [6].

\section{Blood pressure measurement monitoring (non-invasive)}

Shock is defined as a state of effective tissue hypoperfusion, not necessarily with arterial hypotension, commonly diagnosed alternately by presenting lactate above normal values ( $>2$ to 4 $\mathrm{mmol} / \mathrm{L})$ [7].

The pragmatic definition always included a Systolic Blood Pressure (SBP) below $90 \mathrm{mmHg}$ and a Diastolic Blood Pressure (DBP) below $40 \mathrm{mmHg}$, however, hypotension can be mostly evident only during the most severe phases, since the mechanisms Homeostatic will try to keep the average blood pressure at a normal level by increasing
Systemic Vascular Resistance (SVR), this mechanism can be lost in states of vasodilatation induced by sedatives or vasodilators, as well as in vasoplegy, in this situation, the increase in SVR is useful to maintain a minimum level of cardiac and cerebral perfusion, but it can be detrimental to the perfusion of other organs, decreasing blood flow and increasing oxygen debt [8].

Many patients with acute heart failure may develop signs of peripheral disease and anaerobic metabolism without hypotension [8]. On the contrary, the high Mean Blood Pressure (MAP) at the expense of increased SVR can be detrimental, affecting systolic ejection, worsening oxygen delivery, in the same way, patients with acute bleeding will try to keep TAM within the normal value by increasing the adrenergic tone that will recruit the unstressed volume of the venous reservoir and increased arterial tone, however, if the bleeding is not immediately controlled, this compensatory mechanism becomes harmful and will lead to multiple organ failure and death.

The state of shock should be suspected in the context of a known patient with hypertension when there is a decrease in AST greater than $20 \%$ to the figures of BP that the patient is accustomed, this criterion comes from the assumption that under a certain MAP, the Organ blood flow depends on pressure, while above that point blood flow can be considered constant [9].

Hypotension is frequently associated with shock conditions, but in many cases, shock can begin without a decrease in blood pressure, and it can be a very late sign of shock. Therefore, hypotension may be evident in the previous context or if blood loss is more than half of the circulating volume [10].

MAP is considered the necessary pressure for perfusion of vital organs, when MAP falls below the lower limit of self-regulation, regional blood flow becomes linearly dependent on MAP. In some pathological environments, and in specific vascular areas, MAP underestimates the true perfusion pressure, due to marked increases in venous pressure or extravascular pressure at the level of outflow. There is no universal way or threshold of MAP to ensure that blood flow is independent of blood pressure in vital organs. In fact, the critical level of MAP probably differs between the organs and depends on numerous factors, including age, history of hypertension, neurovegetative state, so it should be emphasized in independent organic perfusion pressures [11].

From the mere figure of blood pressure, hemodynamic condition data can be obtained, systolic blood pressure is the one recorded when the volume of ejection of the heart collides with the arterial walls, therefore, a decrease in BP with a predominance of SBP will be mostly caused by a decrease in systolic volume, (hypovolemic, cardiogenic or obstructive shock), at least temporarily, the pulse pressure, which is the difference between the SBP and the PAD, decreases in these situations, also, the PAD represents mostly the vascular tone of the arteries, therefore, a decrease in BP mostly dependent on ADT should make us suspect a state of vasodilation (eg septic shock, anaphylactic, neurogenic), so that in these circumstances a patient may have hypotension without a significant decrease in pulse pressure.

Pulse pressure: Systolic blood pressure - Diastolic blood pressure

\section{Pulse assesment}


Palpating the patient's pulse can give us quick information about his hemodynamic state, when radial pulse is perceived, it can be inferred that the patient has a PAS $>100 \mathrm{mmHg}$, when the brachial pulse is perceived, it is inferred that a PAS> $80 \mathrm{mmHg}$ is inferred and when Only the carotid pulse is perceived, it is estimated that the patient has at least $60 \mathrm{mmHg}$ of PAS, when there is no radial pulse, we should immediately look for the cause of the drop in blood pressure and resolve it as soon as possible [12].

\section{Pulse pressure}

Hemodynamic variable easily measured that is the result of the subtraction of systolic blood pressure minus diastolic blood pressure and whose normal value is around $40 \mathrm{~mm} \mathrm{Hg}$.

Pulse pressure: Systolic blood pressure -Diastolic blood pressure $(\mathrm{PP}=\mathrm{SP}-\mathrm{DP})$

Systemic pulse pressure is approximately proportional to systolic volume (assessing cardiac pump function, preload and afterload) and inversely proportional to the distensibility of the arterial system, especially the aorta. It is a simple way of assessing ventricular elastance and arterial instability, shaping the arterial ventricle coupling. The arterial system performs the function of cushioning the volume ejected by the left ventricle. If the pulse pressure is extremely low, that is: less than $25 \mathrm{mmHg}$ or less, the cause may be low systolic volume such as hypovolemia, cardiogenic shock or obstructive shock, it may also be caused by congestive heart failure or stricture of the aortic valve In the case of a hypotensive patient with a state of shock, maintaining a normal pulse pressure suggests that the most likely cause is vasodilation [13].

\section{Heart rate assesment (HR)}

All cardiac myocytes in the embryonic heart have pacemaker properties. Some myocytes synthesize large amounts of contractile proteins to become "functional" myocardium, others retain the ability of pacemakers and generate electrical impulses. The Sinoatrial Node (SA) in humans is about $8 \mathrm{~mm}$ long and $2 \mathrm{~mm}$ thick. It is found in the groove where the superior vena cava joins the right atrium. The autonomic nervous system controls various aspects of cardiac function, including the frequency with which the heart beats, however, cardiac function does not require all intact nerve pathways since a completely denervated heart (a heart transplant recipient) can adapt well to stressful situations.

The pacemaker trigger frequency is usually controlled by the activity of both divisions of the autonomic nervous system. The increase in sympathetic nerve activity, through the release of nor epinephrine and adrenaline, increases the heart rate mainly by increasing the slope of the pacemaker's potential, this mechanism of increasing the heart rate works during physical exertion, anxiety and certain diseases, such as febrile infectious diseases. On the contrary, the increase in vagal activity, through the release of acetylcholine, decreases the heart rate by hyperpolarizing the pacemaker's cell membrane and reducing the slope of the SA node potential.

Cardiac Output (CO) depends on Heart Rate (HR) and Stroke Volume (SV); the increase in heart rate being the most important mechanism to increase cardiac output quickly.

Cardiac output $=$ Heart rate $\times$ stroke volume.
Tachycardia, defined as a heart rate $>100$ beats/min regularly occurs in situations of increased metabolic oxygen demand with the need for an increase in cardiac output or in conditions associated with decreased systolic volume with intact myocardium (eg hypovolemic shock or obstructive) due to the decrease in preload (volume decrease) and also in situations of impaired systolic heart function. Since tachycardia reduces the diastolic time during which ventricular filling occurs, systolic volume may decrease at high heart rates, this has its highest expression in unstable or symptomatic tachyarrhythmias (example: supra ventricular tachycardia with low cardiac output data ); This, however, only becomes clinically significant in patients with myocardial relaxation disorders that cause decreased diastolic filling. Tachycardia also occurs in situations of increased sympathetic tone, that is, pain, anxiety and combative response.

Sinus tachycardia is always an undesirable sign, and its cause must always be determined. An initial CF> 105/min and a sustained $\mathrm{HR}>90$ to 95 beats/min in patients with shock status are associated with an increased risk of death [14].

The higher the HR, the more severe the situation, the HR decreases with age, so an HR> 110/min in an elderly patient is a very worrying sign. The clinical context and disorders of the other vital signs are important to assess the implications of a tachycardia.

Tachycardia in combination with hypotension $(\mathrm{SBP}<110$ or $\mathrm{MAP}<75 \mathrm{mmHg})$ and a high respiratory rate $(>20 / \mathrm{min})$ should make us think about performing interventions on the patient [15]. It should be emphasized that, in almost all circumstances, one should treat the underlying cause (if possible) of the tachycardia and not the tachycardia itself, this is very routine in daily practice with adding a beta-blocker to the indications however You run the risk of increasing the chance of an acute adverse cardiac event. However, in patients with diastolic dysfunction, reducing HR can improve diastolic filling, therefore, increase systolic volume and improve macrohemodynamic variables such as an increase in $\mathrm{BP}$, in refractory septic shock this possibility can be considered with beta-blocker. intravenous with HR goal close to $90 / \mathrm{min}$.

In an episode of HR> 150/min (SVT) without underlying extracardiac cause it should be considered to use intravenous vagal or anti-arrhythmic maneuvers, in case the SVT is accompanied by symptoms (hypotension, chest pain, dyspnea, neurological alteration, etc.) it should alert to take an immediate action to reduce the HR that corresponds to a synchronized electrical cardioversion and possibly the use of anti-arrhythmic drugs in case of not obtaining a good therapeutic response.

At the other end we have bradycardia. Sinus bradycardia is defined as a heart rate of less than 60 beats/min. Patients with sinus bradycardia usually have a frequency between 45 and 59 beats/min, but rarely can be as slow as 30 beats/min. Sinus bradycardia is often benign and does not necessarily indicate sinus node dysfunction.

In the context of the critical patient, sinus bradycardia is most often due to a pharmacological reaction (eg sedatives), but it can occur in patients with intrinsic disease of the conductive tissues of the heart. Bradycardia can also present before, hypothermia, hypothyroidism and elevated intracranial pressure. The medications most commonly involved include beta blockers, calcium antagonists, dexmedetomidine, Propofol, clonidine and digoxin. 


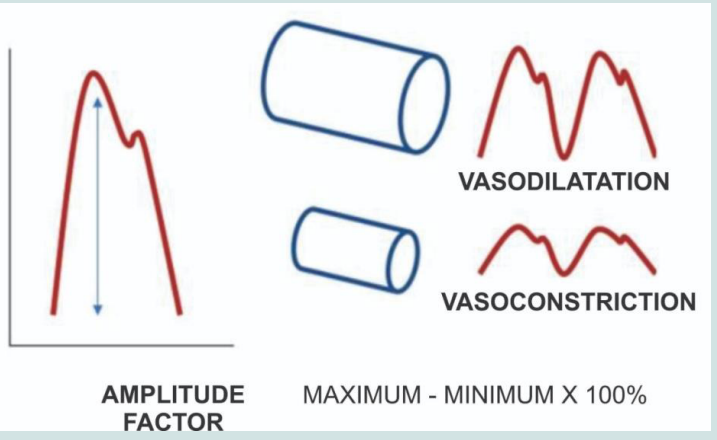

Figure 1: Scheme of the plethysmographic variability index (IVP): maximum pulse pressure (PPmax) - minimum pulse pressure (PPmin) / (PPmax + $\mathrm{PPmin}$ ) / 2 to determine the volume response. An PVI> $14 \%$ is associated with a patient responding to volume.

Dexmedetomidine, an alpha-2 receptor agonist, decreases the production and response to catecholamines and leads to bradycardia due to these sympatholytic effects. Proprofol induces bradycardia by blocking calcium and potassium channels in heart cells. While Propofol and dexmedetomidine alone have a relatively low incidence of bradycardia when used in combination with other AV nodal block medications, the risk of bradycardia increases [15].

Bradycardia $<50$ beats/minute accompanied by symptoms (hypotension, dyspnea, neurological disturbance, chest pain, etc.) indicates that we should start an immediate treatment, the use of atropine is recommended in this situation, if it is not resolved, a chronotropic can be used positive as dopamine in infusion and consider the use of a pacemaker.

\section{Assesment of the plethysmographic curve}

One of the hemodynamic assessment tools available from the pre-hospital environment, to the emergency room and other critical areas is the plethysmographic wave analysis observed with the pulse oximeter. The plethysmographic pulse wave figure is illustrated as a mirror image of the pulsatile vessel light intensity wave, whose variations in wave size are due to changes in local blood volume and vascular resistance [16].

The shape of the plethysmographic pulse curve can provide information on the current state of peripheral vascular resistance and the heartbeat volume. The amplitude of the plethysmographic wave is related to the vascular state of the peripheral arteries as follows: the larger the amplitude of the wave, this will be associated with a mild, moderate or severe vasodilation, on the contrary, the smaller this amplitude will be related to peripheral arterial vasoconstriction. Likewise, the position of the notch of the dicrota wave in relation to the level of amplitude of the maximum systolic peak does not offer certain information: if the position of the notch is above $50 \%$ of the amplitude, the tendency will be vasoconstriction, instead If the position of the notch of the dicrota wave is below $50 \%$ of the amplitude of the plethysmographic wave, the tendency will be peripheral arterial vasodilation. Clinically we can infer that a patient who presents hypotension accompanied by a plethysmographic vasodilation pattern, the type of causal shock will be distributive (vasodilated), in case, on the contrary, it is associated with a vasoconstriction pattern, it is inferred that the type of Shock will be one that affects systolic volume (hypovolemic, cardiogenic, obstructive) (Figure 1and 2) [17].

\section{Shock Index and Modified shock index}

The Shock Index (SI) is a rapidly obtained parameter that indicates severity and tendency in the patient, which is the result of dividing the heart rate between systolic blood pressure, due to its simplicity and applicability have been the subject of study by different authors, so that if it is elevated, it can be assumed that there is a decrease in systolic volume or a decrease in systemic vascular resistance [18].

The normal range of the shock index for healthy adults is 0.5 to 0.7. In non-pregnant patients, the shock index is useful for detecting shock at early stages, even more than conventional vital signs, especially in patients with trauma shock or sepsis of non-specific origin.

The Modified Shock Index (MSI) is a variant determined by heart rate and Mean Blood Pressure (MAP), a reported cut $(<0.7$ and $>$ 1.3) as a better predictor of mortality than the conventional shock index. A study that analyzed more than 9000 patients who went to the emergency room concluded that the MSI was significantly better than clinical parameters such as HR, SBP, DBP and SI only to predict mortality. The MSI has been highly associated with mortality is above 1.8 [19].

Anything that increases HR or decreases BP will modify SI, so the clinical picture must be taken into account. Among the factors that can modify the SI and the MSI are the presence of pain and anxiety, which can cause tachycardia and thereby increase the values of the indices, or the measurement of blood pressure with manual or automatic systems. It is known that taking blood pressure with automatic systems increases blood pressure and thereby decreases the values of these indices [20].

\section{Perfusion windows}

\begin{tabular}{|c|c|c|c|c|c|c|}
\hline \multirow{2}{*}{$\begin{array}{c}\text { Vascular } \\
\text { Tone }\end{array}$} & \multirow{2}{*}{ Normal } & \multicolumn{2}{|c|}{ Vasoconstriction } & \multicolumn{3}{|c|}{ Vasodilation } \\
\hline & & Severe & Moderate & Mild & Moderate & Severe \\
\hline $\begin{array}{l}\text { Wave } \\
\text { Form }\end{array}$ & & & & & & \\
\hline Amplitude & $=$ & .. & at & $\uparrow$ & $\uparrow \uparrow$ & $\uparrow \uparrow \uparrow$ \\
\hline $\begin{array}{l}\text { Notch } \\
\text { Position }\end{array}$ & $=$ & $\uparrow \uparrow \uparrow$ & $\uparrow \uparrow$ & , & ". & 116 \\
\hline
\end{tabular}

Figure 2: Types of plethysmographic wave.

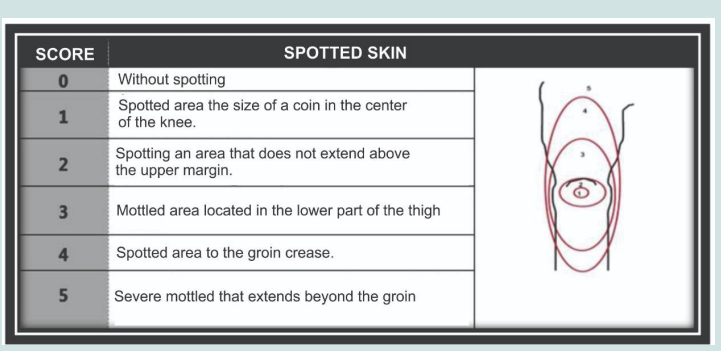

Figure 3: Evaluation of the skin in shock. 


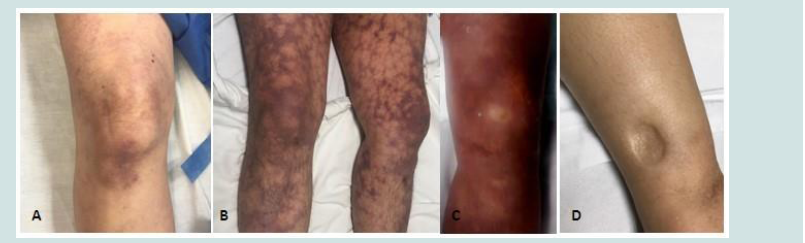

Figure 4: Cutaneous data of clinical relevance. A: Spotting score of 3, B spotting score of 5 , C: delayed capillary filling $>5 \mathrm{~s}$, D: over water resuscitation.

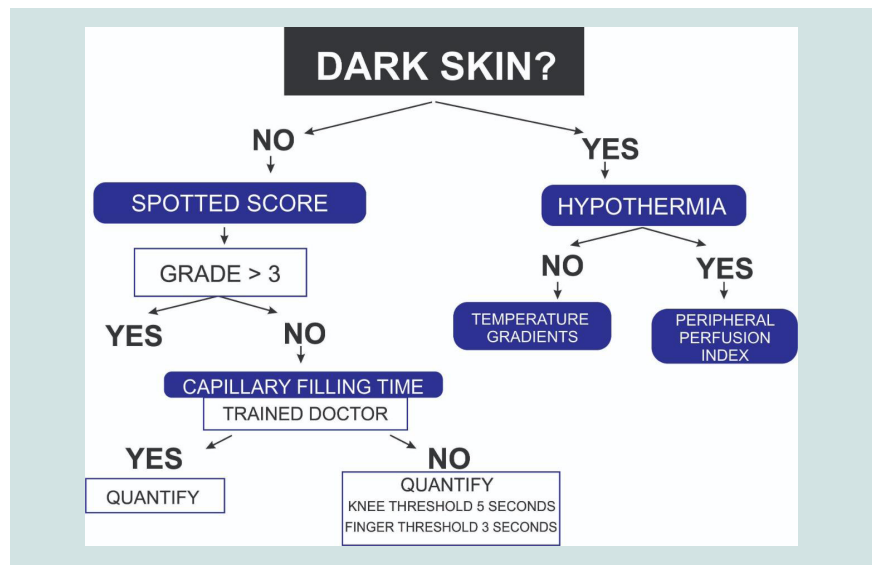

Figure 5: Hemodynamic monitoring proposal by skin condition.

Since 1961 it is stated that it may be better to recognize the state of shock than to define it, so we must direct the intentional search for this pathological state through the clinical windows, which give us a wide and accurate picture of the patient taking tissue perfusion ineffective [21].

\section{Mental status}

Changes in mental state occur early in the course of circulatory failure. Recent developments in scoring systems have revealed that changes and fluctuations in mental state and/or attention, the presence of disorganized thinking and an altered level of consciousness are related to an abnormal brain function, which may be caused by alterations in cerebral oxygen supply and/or decrease in microcirculatory perfusion at that level [22].

We will set the stage for a state of shock with decreased cardiac output, both low cardiac output and low blood pressure contribute to changes in perfusion and brain function [23]. In the so-called distributive shock, cardiac output is preserved, but the Loss of self-regulatory mechanisms due to the activation of Nitric Oxide Synthetase (iNOS) may result in abnormalities of micro circulatory perfusion leading to the loss of adequate perfusion and function [24]. In case of septic shock, the inflammatory response to the infection itself leads to changes in mental status [25], nowadays it is generally known as encephalopathy associated with sepsis, where changes in metabolism can cause an abnormal disorder. Mental status in these patients similar to delirium status.

Like many clinical signs described in the field of circulatory insufficiency, a change in mental status is neither sensitive nor specific. However, a patient who has a sudden change (hours) in brain function should be carefully examined for possible circulatory failure, while an abnormal mental state in a patient with clear circulatory failure may be a warning sign that a patient It is reaching the limits of compensatory mechanisms [26].

\section{Temperature}

The skin is the main organ in thermoregulation and has no selfregulating mechanisms; A decrease in skin perfusion results in a decrease in local temperature. Understanding that cold and moist skin has long been seen as an important symptom of impaired circulation of different origins [27], therefore, cold skin, even in patients with sepsis, is an early sign of circulatory failure [28]. Few studies have demonstrated abnormal hemodynamic profiles in patients with cold skin to the touch, most of them corresponding to cardiogenic shock.

A mixed cohort review showed that cold skin patients were associated with lower cardiac output (GC), mixed mixed venous oxygen saturation and higher lactate levels. A sweaty skin and cold to the touch can correlate with elevated lactate levels, high veno-arterial difference of $\mathrm{CO}_{2}\left(\mathrm{DvaCO}_{2}\right)$ high and low $\mathrm{SvcO}_{2}$.

The difference of the central temperature at the feet (Tc-toe) has been a proposed strategy such as the difference between the central temperature measured in tympanic membrane and the temperature in the ventral surface of the big toe that has been used as a measure of vasoconstriction peripheral as a result of a shock state, however it has the disadvantage of being affected by hypothermia and the ambient temperature.

The temperature gradient between the tip of the finger and the forearm (Tskin-diff) has also been used as a marker of peripheral vasoconstriction peripheral Tskin-diff is the difference between the temperatures on the index finger and on the radial side of the forearm, which It has the advantage of not being affected by the environment because the change in external temperature affects both the fingertip and the forearm alike.

\section{Skin}

The skin is the first organ to sacrifice blood flow before a state of circulatory shock, so it will give visible manifestations quickly and with an adequate correlation with other clinical and biochemical parameters of tissue hypoperfusion at other levels. A pale or mottled skin recognized early indicates strong suspicion of inadequate tissue perfusion. In current reviews (Coudroy col) [29]; It was found that almost a third of the patients admitted to the ICU had mottled skin, while this was present in almost $50 \%$ of patients with septic shock since their admission to the emergency area.

Spotted skin is defined as "irregular skin coloration" and is the result of heterogeneous vasoconstriction of the small peripheral vessels, skin spots usually manifest around the knees and may extend to other peripheral circulation sites such as fingers and ears Initially When mottled skin is observed over a large area, it is a sign that the patient is in danger of death, patients with a higher speckled score are more likely to die even on the first day of admission, therefore it should be considered an emergency Medical regardless of blood pressure, it is important to mention that mottling is not modified with pressure on the skin on physical examination [30].

There is a direct relationship in the mottle score with the amount of serum lactate, the latter being a faithful marker of lethality in the absence of other possible causes of hyperlactatemia such as previous 


\begin{tabular}{|c|c|c|c|c|c|c|c|}
\hline TYPE OF SHOCK & SYMPTOMATOLOGY & HEART FREQUENCY & SKIN & $\mathrm{SAO2}$ & PULSE PRESSURE & $\begin{array}{l}\text { PIETISMOGRAPHIC } \\
\text { WAVE }\end{array}$ & $\begin{array}{l}\text { IMMEDIATE } \\
\text { TREATMENT }\end{array}$ \\
\hline HYPOVOLEMIC & $\begin{array}{l}\text { Hemorrhage: trauma, } \\
\text { visible bleeding or } \\
\text { suspected occult } \\
\text { bleeding. } \\
\text { Dehydration: } \\
\text { diarrhea, nausea, } \\
\text { vomiting. }\end{array}$ & $\uparrow \uparrow$ & cold & Normal & $\downarrow$ & & $\begin{array}{l}\text { Hemorrhage: stop } \\
\text { bleeding, IV fluid } \\
\text { therapy, hemostatic, } \\
\text { blood products. } \\
\text { Dehydration: oral or } \\
\text { IV hydration. }\end{array}$ \\
\hline CARDIOGENIC & $\begin{array}{l}\text { Thoracic pain, } \\
\text { trauma, anginal } \\
\text { equivalents. } \\
\text { valvulopathies }\end{array}$ & $\uparrow \downarrow$ & cold & $\begin{array}{c}\text { Normal or left } \\
\text { ventricular infarction }\end{array}$ & $\downarrow$ & & $\begin{array}{l}\text { Inotropic, } \\
\text { vasopressor, } \\
\text { reperfusion, } \\
\text { ventricular support, } \\
\text { cardiac surgery. }\end{array}$ \\
\hline OBSTRUCTIVE & $\begin{array}{l}\text { Tamponade: thoracic } \\
\text { trauma, pericarditis, } \\
\text { pericardial effusion. } \\
\text { Tension } \\
\text { pneumothorax: } \\
\text { thoracic trauma, } \\
\text { COPD. } \\
\text { PET: thrombophilias, } \\
\text { prostration, cancer, } \\
\text { etc. }\end{array}$ & $\uparrow$ & cold & $\begin{array}{l}\text { Normal and in PET } \\
\text { and pneumothorax }\end{array}$ & $\downarrow$ & & $\begin{array}{l}\text { Tamponade: } \\
\text { pericardial } \\
\text { drainage or, } \\
\text { Tension } \\
\text { pneumothorax: } \\
\text { pleural drainage. } \\
\text { PET: thrombolysis, } \\
\text { thrombectomy, } \\
\text { etc. }\end{array}$ \\
\hline $\begin{array}{l}\text { VASODILATE } \\
\text { (DISTRIBUTIVE }\end{array}$ & $\begin{array}{l}\text { Sepsis: fever, } \\
\text { suspected infection } \\
\text { or confirmed } \\
\text { infection. } \\
\text { Anaphylaxis: } \\
\text { Allergens, drugs. } \\
\text { Neurogenic: spinal } \\
\text { cord trauma, TBI. }\end{array}$ & $\uparrow$ & Hot & Normal & $\uparrow$ & & $\begin{array}{l}\text { Sepsiss: Antibiotic, } \\
\text { vasopressor, fluids. } \\
\text { Anaphylaxis: } \\
\text { Vasopressor } \\
\text { (adrenaline). } \\
\text { Neurogenic: } \\
\text { Vasopressor, } \\
\text { chronotropics, } \\
\text { surgery. }\end{array}$ \\
\hline
\end{tabular}

Figure 6: Evaluation of the types of shock by clinical monitoring.

liver disease, drug exposure and inborn errors of metabolism. Oufella et al. they found a direct relationship between mottled and lactate with a $\mathrm{p}=0.0001[31]$.

There are several mechanisms involved associated with mottled skin: a poor distribution of blood flow, loss of vascular self-regulation and an increase in metabolites of nitric oxide synthetase. The mottled index proposes six degrees associated with gravity, (0 to 5) and depends on the extent of the mottled skin up the knee. Higher spotting index score (score of 4 to 5 ) is associated with high mortality in patients with septic shock. Spotted skin prolonged for more than $6 \mathrm{~h}$ was associated with higher mortality in the ICU regardless of scoring systems severity (Figure 3) [32].

\section{Capillary filling time}

The capillary filling time measures the amount of time necessary for the skin to return to its initial color after applying pressure for a few seconds on a soft tissue (usually finger or knee area), initially used as a diagnosis and monitoring of patients Pediatric patients with hypovolemic shock because it provides important information on skin perfusion and microcirculatory status and is an attractive and easy-to-use tool for doctors in the initial detection of critical patients [33].

It is recommended to perform it by applying firm pressure for $15 \mathrm{~s}$, long enough to remove blood from the nail bed. It has been shown that capillary filling time is related to more objective perfusion measurements, even than temperature gradients. Capillary filling under normal conditions lasts less than $2 \mathrm{~s}$, values greater than 2.5 to $5 \mathrm{~s}$ are associated with higher mortality, especially if they persist steadily and have a direct association with elevated serum lactate, elevated $\mathrm{DvaCO}_{2}$ and decreased $\mathrm{SvcO}_{2}$.

The evaluation of capillary filling measured by applying firm pressure to the ventral surface of the right index finger, for $10 \mathrm{~s}$, the time for the return of normal skin color was considered abnormal
$>3$ s corresponding to a lactate value $\geq 2.0 \mathrm{mmol} / \mathrm{L}$, both as tissue hypoperfusion data $[4,34]$. To date, the best evidence with statistical significance emphasizes the time of capillary filling with better utility in the evaluation of patients with circulatory insufficiency [35].

\section{Uresis}

One of the main functions of the kidney, is to filter the blood and eliminate waste and excess fluids, an early sign of an impaired renal perfusion is the decrease in urine production, in a standardized way oliguria is taken as a uresis $<400$ at $500 \mathrm{ml} /$ day or $<0.5$ to $1 \mathrm{ml} /$ $\mathrm{kg} / \mathrm{h}$. Renal injury can occur due to decreased cardiac output, but also due to direct inflammation in the nephron, which is the case of sepsis, even a worsening of the renal lesion has been described in patients with sepsis and septic shock to which it is applied increased contribution of crystalloid or colloid volume of hydroxyethyl-starch type, which suggests that the renal lesion in pro-inflammatory states is not volume dependent, but of inflammation to the nephron per se.

Studies of patients with early septic shock and post-operated cardiac surgery have shown to have significantly lower urine output despite a similar macro-hemodynamics [36]. The reason for this dissociation is multifactorial, since many factors are related to the decrease in renal function in sepsis. However, tubular injury is unlikely to be a concomitant factor; the term acute tubular necrosis should be avoided to address renal dysfunction in acute circulatory insufficiency, especially if it is associated with a systemic inflammatory response [37].

The presence of a decrease in urine production with a threshold of $0.5 \mathrm{ml} / \mathrm{kg} / \mathrm{h}$ represents a specific and sensitive parameter to diagnose and treat acute circulatory insufficiency due to the risk of renal insufficiency and associated mortality (Figure 4 and 5).

\section{Discussion}

Clinical hemodynamic monitoring at the patient's bedside is a 
Citation: Pérez Nieto OR, Guerrero Gutiérrez MA, MorgadoVillaseñor LA, Fermín JL, Zamarrón López El, et al. Hemodynamic Monitoring with the Clinic: Back to Basics. J Emerg Med Critical Care 2020;6(1): 7.

useful tool, free of charge, highly reproducible and with evidence that supports its efficacy compared to other minimally invasive or invasive methods. Hassanin has described the applicability of clinical perfusion indices: delayed capillary filling, mottling score and its relationship with the patient's prognosis, which provide the same information as other methods such as central venous oxygen saturation or venoarterial difference of $\mathrm{CO}_{2}$, without the need to perform a puncture and laboratory analysis.

The ANDROMEDA randomized controlled study presented a holistic vision based on pathophysiology and physiology with goalguided therapy, observing that a CRT $>3 \mathrm{~s}$ corresponds to a lactate value $\geq 2.0 \mathrm{mmol} / \mathrm{L}$, these data corresponding to effective tissue hypoperfusion, the manuscript concludes that there is no added benefit when measuring lactate compared to the CRT measurement, generating a better use of resources due to cost reduction, it is even associated with prevention of over-resuscitation and evidencing decrease in mortality at 28 days when goal-guided therapy is performed.

The use of capillary filling time, mottle score and other clinical features such as tissue perfusion indices require a significant context, using it as a universal detection tool in each patient could have limited value in some cases (skin patients obscure, patients without lower extremities, patients with previous neurological alteration, etc.), however of the available studies, the clinic is present in all cases, it should not be forgotten that the worst hemodynamic monitoring is the one that "is not done" and having the premise that "less is more", however, it is prudent to consider whether the patient requires another type of more advanced evaluation in the clinical course of his pathology in case of not obtaining good results with the initial therapy.

\section{Conclusion}

The clinic is a useful tool, highly reproducible and with good correlation with other markers of tissue perfusion, it is recommended to use it for early diagnosis of the states of shock and tissue hypoperfusion, as well as monitoring the therapeutic response to the patient's bedside, we summarize the main clinical scenarios in figure 6, with this you can evaluate your patients through clinical monitoring.

\section{References}

1. Jean-Louis V, De Backer D (2013) Circulatory Shock. N Engl J Med 369 1726-1734.

2. Hiemstra B, Eck R, Keus F, van der Horst ICC (2017) Clinical examination for diagnosing circulatory shock. Curr Opin Crit Care 23: 293-301.

3. Hernández G, Bruhn A, Castro R, Regueira T (2012) The holistic view on perfusion monitoring in septic shock. Curr Opin Crit Care 18: 280-286.

4. Hernández G, Cavalcanti A, Ospina-Tascon, Godinho Zampieri F, Dubin A, e al. (2018) Early goal-directed therapy using a physiological holistic view: The andromeda-shock - a randomized controlled trial. Ann Intensive Care 8: 52.

5. Ince C (2015) Hemodynamic coherence and the rationale for monitoring the microcirculation. Crit Care 19: S8.

6. Rhodes A, Evans LE, Alhazzani W, Levy MM, Antonelli M, et al. (2017) Surviving sepsis campaign: international guidelines for management of sepsis and septic shock: Intensive Care Med 43: 304-377.
7. Sheldon M (2012) Bench-to-bedside review: An approach to hemodynamic monitoring - Guyton at the bedside. Crit Care 16: 236

8. Ait-Oufella H, Bakker J (2016) Understanding clinical signs of poor tissue perfusion during septic shock. Intensive Care Med 42: 2070-2072.

9. Brunauer A, Kokofer A, Bataar O, Gradwohl-Matis I, Dankl D, et al. (2016) Changes in peripheral perfusion relate to visceral organ perfusion in early septic shock: a pilot study. J Crit Care 35: 105-109.

10. Hernández G, Luengo C, Bruhn A, Kattan E, Friedman G, et al. (2014) When to stop septic shock resuscitation: clues from a Dynamic perfusion monitoring. Ann Intensive Care 4: 30

11. Ait-Oufella H, Bige N, Boelle PY, Pichereau C, Alves M, et al. (2014) Capillary refill time exploration during septic shock. Intensive Care Med 40: 958-964.

12. Hasanin A, Mukhtar A, Nassar H (2017) Perfusion indices revisited. J Intensive Care 5: 24

13. Bourgoin A, Leone M, Delmas A, Garnier F, Albanèse J, et al. (2005) Increasing mean arterial pressure in patients with septic shock: Effects on oxygen variables and renal function. Crit Care Med 33: 780-786.

14. Hamzaoui O, Teboul JL (2016) How do I integrate hemodynamic variables when managing septic shock? Korean J Crit Care Med 31: 265-275.

15. Hariri G, Joffre J, Leblanc G, Bonsey M, Jean-Remi L, et al. (2019) Narrative review: Clinical assessment of peripheral tissue perfusion in septic shock. Ann Intensive Care 9: 37.

16. Shalley K (2007) Photoplethysmography: Beyond the calculation of arteria oxygen saturation and heart rate. Anesth Analg 105: S31-S36.

17. Elgendi M (2012) On the analysis of fingertip photoplethysmogram signals Curr Cardiol Rev 8: 14-25.

18. Smischeney N, Mohamed O, Heise K, Schroeder DR, Weister TJ, et al. (2018) Elevated Modified Shock IndexWithin24 Hours of ICU Admission Is Indicator in the Critically III. J Intensive Care Med 33: 582-588.

19. Terceros-Almanza LJ, García-Fuentes C, Bermejo-Aznárez S, Prieto-Del IJ, Mudarra-Reche P, et al. (2017) Prediction of massive bleeding. Shock index and modified shock index. Med Intensiva 41: 532-538.

20. Singh A, Ali S, Agarwal A, Srivastava RN (2014) Correlation of shock index and modified shock index with the outcome of adult trauma patients a prospective study of 9860 patients. N Am J Med Sci 6: 450-452.

21. Millham FH (2010) A brief history of shock. Surgery 5: 1026-1037.

22. Ceconni M, De Backer D, Antonelli M, Beale R, Bakker J, et al. (2014) Consensus on circulatory shock and hemodynamic monitoring. Task Force of the European society of intensive care medicine. Intensive Care Med 40: $1795-1815$

23. Mizota T, Yamamoto Y, Hamada M, Matsukawa S, Shimizu S, et al. (2017) Intraoperative oliguria predicts acute kidney injury after major abdominal surgery. Br J Anaesth 119: 1127-1134.

24. van Genderen ME, Engels N, van der Valk R, Lima A, Klijn E, et al. (2015) Early peripheral perfusion-guided fluid therapy in patients with septic shock. Am J Respir crit care med 191: 477-480.

25. Morimura N, Takahashi K, Doi T, Ohnuki T, Sakamoto T, et al. (2015) A pilot study of quantitative capillary refill time to identify high blood lactate levels in critically ill patients. Emerg Med J 32: 444-448.

26. Leedahl DD, Frazee EN, Schramm GE, Dierkhising RA, Bergstralh EJ, et al. (2014) Derivation of urine output thresholds that identify a very high risk of AKI in patients with septic shock. Clin J Am Soc Nephrol 9: 1168-1174.

27. Bourcier S, Pichereau C, Boelle PY, Nemlaghi S, Dubée V, et al. (2016) Toeto-room temperature gradient correlates with tissue perfusion and predicts outcome in selected critically ill patients with severe infections. Ann Intensive Care 6: 23

28. Kaplan L, McPartland K, Santora TA, Trooskin SZ (2001) Start with a subjective assessment of skin temperature to identify hypoperfusion in intensive care unit patients. J Trauma 50: 620-627. 
Citation: Pérez Nieto OR, Guerrero Gutiérrez MA, MorgadoVillaseñor LA, Fermín JL, Zamarrón López El, et al. Hemodynamic Monitoring with the Clinic: Back to Basics. J Emerg Med Critical Care 2020;6(1): 7.

29. Coudroy R, Jamet A, Jean-Pierre F, Veinstein A, Chatellier D, et al. (2014) Incidence and impact of skin mottling over the knee and its duration on outcome in critically ill patients. Intensive Care Med 41: 452-459.

30. De Moura EB, Armorim FF, Da Cruz S AN, Kanhouche G, de Souza Godoy LG, et al. (2016) Skin mottling score as a predictor of 28-day mortality in patients with septic shock. Intensive Care Med 42: 479-480.

31. Lara B, Enberg L, Ortega M, Leon P, Kripper C, et al. (2018) Capillary refil time during fluid resuscitation in patients with sepsis-related hyperlactatemia at the emergency department is related to mortality. PLoS One 12: e0188548.

32. Ferraris A, Bouisse C, Mottard N, Thiollière F, Anselin S, et al. (2018) Mottling score and skin temperature in septic shock: relation and impact on prognosis in ICU. PLOS One 13: e0202329.

33. Pickard A, Karlen W, Ansermino JM (2011) Capillary Refill time: is it still a useful clinical sing? Anesth Analg 113: 120-123.
34. Cecconi M, Hofer C, Jean-Louis T, Pettila V, Wilkman E, et al. (2015) Fluid challenges in intensive care: the FENICE study: a global inception cohort study. Intensive Care Med 41: 1529-1537.

35. Dumas G, Jean-Remi L, Joffre J, Bigé N, De-Moura EB, et al. (2019) Mottling score is a strong predictor of 14-day mortality in septic patient's whatever vasopressor doses and other tissue perfusion parameters. Critical care 23: 211.

36. Larsson LS, Krumbholz V, Enskog A, Bragadottir G, Redfors B, et al. (2018) Renal blood flow, glomerular filtration rate, and renal oxygenation in early clinical septic shock. Crit Care Med 46: e560-e566.

37. Schortgen F, Schetz M (2017) Does this critically ill patient with oliguria need more fluids, a vasopressor, or neither? Intensive Care Med 43: 907-910. 